\title{
Intracardiac right-to-left shunts demonstrated by two-dimensional echocardiography after peripheral vein injection ${ }^{1}$
}

\author{
PATRICK W. SERRUYS, MARCEL VAN DEN BRAND, PAUL G. HUGENHOLTZ, \\ AND JOS ROELANDT, with the technical assistance of Ben Dielhof, Els W. Leuftink, and \\ Wim B. Vletter \\ From the Department of Clinical Echocardiography, Thoraxcenter, Academic Hospital Dijkzigt, and \\ Erasmus University, Rotterdam, the Netherlands
}

SUMMARY The usefulness of performing real time cross-sectional echo contrast studies, using peripheral venous injections of dextrose 5 per cent in water, for the detection and localisation of atrial and ventricular right-to-left shunts was evaluated in 70 adult patients. Based on their catheterisation data, 20 patients had a shunt at atrial level (group 1) and 14 patients a ventricular septal defect (group 2). Thirty-six patients without a shunt by oximetry served as controls. Echo contrast could not be detected in the left-sided cardiac cavities in any of the control patients.

In 11 of the 15 patients with an uncomplicated atrial septal defect of the secundum type, echo contrast appeared at the left side of the heart and this small right-to-left shunting occurred in systole. Left-sided echo contrast was demonstrated in the 5 patients in whom a bidirectional atrial shunt was found by oximetry.

Of the 14 patients with a ventricular septal defect, 7 had a ratio of right-to-left ventricular pressure exceeding 50 per cent and early diastolic right-to-left shunting of echo contrast was observed in all. This was not seen in any of the patients with an uncomplicated ventricular septal defect.

Diagnostic real time ultrasonic cross-sectional contrast studies can thus be performed in adults using peripheral venous injections of dextrose 5 per cent in water. The presence and timing of intracardiac right-to-left shunts, even when small, are greatly facilitated.

The concept of contrast echocardiography was introduced in the late sixties by Gramiak and his group, primarily to identify intracardiac structures (Gramiak and Shah, 1968; Gramiak et al., 1969; Feigenbaum et al., 1970). Subsequently, intracardiac injections of echo contrast material were found useful in the assessment of congenital heart disease, as a complementary technique to conventional catheterisation methods (Pieroni et al., 1973; Kerber et al., 1974; Seward et al., 1975). Contrast echocardiography found rapid acceptance in the echocardiography laboratory after it was shown by Valdes-Cruz et al. (1976) that peripheral vein injection of a Cardiogreen solution produced sufficient ultrasonic contrast to define intracardiac shunts.

The present study was undertaken to evaluate

${ }^{1}$ Supported in part by a grant from the Inter-University Cardiology Institute of the Netherlands.

Received for publication 7 February 1979 the feasibility and usefulness of performing real time two-dimensional injections of dextrose 5 per cent in water rather than a Cardiogreen solution and to assess its usefulness for the study of intracardiac shunts.

\section{Patients}

Real time cross-sectional contrast studies were performed in 70 patients ( 47 men and 23 women, ages ranging from 17 to 64 years), who were referred to our clinic for cardiac evaluation. All underwent a complete haemodynamic and angiographic study and were divided into 3 main groups.

GROUP 1

This group consisted of 20 patients with an atrial septal defect; in 18 (including 3 patients with Ebstein's anomaly) this was of the secundum type and in 2 of the primum type. 
Table 1 Data of patients with atrial septal defect

\begin{tabular}{|c|c|c|c|c|c|c|c|c|}
\hline $\begin{array}{l}\text { Case } \\
\text { no. }\end{array}$ & $\begin{array}{l}\text { Age (y), sex, } \\
\text { type of } A S D\end{array}$ & $\begin{array}{l}\text { Aortic } \\
\text { saturation } \\
(\%)\end{array}$ & $Q P / Q S$ & $\begin{array}{l}R V S P \\
(m m H g)\end{array}$ & $\begin{array}{l}L V S P \\
(m m H g)\end{array}$ & $\begin{array}{l}R V I D \\
(\mathrm{~mm}) \\
M \text { mode }\end{array}$ & $\begin{array}{l}\text { Paradoxical } \\
\text { septal motion } \\
M \text { mode }\end{array}$ & $\begin{array}{l}\text { Left-sided } \\
\text { echo } \\
\text { contrast }\end{array}$ \\
\hline
\end{tabular}

QP/QS, pulmonary-to-systemic flow ratio; RVSP, right ventricular systolic pressure; LVSP, left ventricular systolic pressure; RVID, right ventricular internal diameter; $\mathbf{A}+$, angiographically proven.

GROUP 2

This group consisted of 14 patients with a ventricular septal defect: 7 with an isolated defect (Table 2) and 7 with associated pathology ( 2 with tetralogy of Fallot, 1 with pulmonary atresia, 1 with truncus arteriosus, 1 with pulmonary hypertension, and 2 with valvar pulmonary stenosis; Table 3 ). The intracardiac shunt ratios of the patients in both groups were derived from standard formulae (Bing et al., 1947) using values (mean of 3 samples) for systemic and pulmonary arterial and mixed venous oxygen saturations: the latter was calculated from superior and inferior vena cava oxygen contents (Flamm et al., 1969). A summary of these data is presented in Tables 1,2 , and 3.

GROUP 3

This group comprised 36 patients in whom no intracardiac shunt was shown during catheterisation and who served as controls.

\section{Methods}

\section{INSTRUMENTATION}

Real time cross-sectional ultrasonic studies were performed using a dynamically focused multiscan system (Ligtvoet et al., 1977). The linear array transducer consists of 51 elements of which subarrays of 12 elements are used for both transmission and reception. In transmission, an axicon focus is applied. During reception, 6 zones are sequentially focused and adjusted to the depth from where the echoes originate at that particular moment. The operating frequency is $3.12 \mathrm{MHz}$. The effective beam width originating from each subarray is $2 \mathrm{~mm}$, yielding a good lateral resolution over the entire

Table 2 Data of patients with isolated ventricular septal defect

\begin{tabular}{|c|c|c|c|c|c|c|c|c|}
\hline $\begin{array}{l}\text { Case } \\
\text { no. }\end{array}$ & $\begin{array}{l}\text { Age }(y), \\
\text { sex }\end{array}$ & $\begin{array}{l}\text { Aortic } \\
\text { saturation } \\
(\%)\end{array}$ & $Q P / Q S$ & $\begin{array}{l}R V S P \\
(\operatorname{mm} H g)\end{array}$ & $\begin{array}{l}L V S P \\
(m m H g)\end{array}$ & $\begin{array}{l}R V I D \\
(\operatorname{mm}) \\
M \text { mode }\end{array}$ & $\begin{array}{l}\text { Paradoxical } \\
\text { septal motion } \\
M \text { mode }\end{array}$ & $\begin{array}{l}\text { Left-sided } \\
\text { echo } \\
\text { contrast }\end{array}$ \\
\hline $\begin{array}{l}1 \\
2 \\
3 \\
4 \\
5 \\
6 \\
7\end{array}$ & $\begin{array}{l}24, M \\
19, M \\
25, M \\
19, M \\
40, F \\
30, F \\
27, F\end{array}$ & $\begin{array}{l}97 \\
97 \\
97 \\
96 \\
97 \\
98 \\
96\end{array}$ & $\begin{array}{l}1.5 \\
1.5 \\
1.7 \\
1.6 \\
2 \\
1.5 \\
1.2\end{array}$ & $\begin{array}{l}29 \\
36 \\
29 \\
25 \\
34 \\
24 \\
18\end{array}$ & $\begin{array}{l}125 \\
132 \\
126 \\
140 \\
114 \\
140 \\
128\end{array}$ & $\begin{array}{l}20 \\
15 \\
25 \\
25 \\
25 \\
20 \\
20\end{array}$ & $\begin{array}{l}\text { No } \\
\text { No } \\
\text { No } \\
\text { No } \\
\text { No } \\
\text { No } \\
\text { No }\end{array}$ & $\begin{array}{l}\text { No } \\
\text { No } \\
\text { No } \\
\text { No } \\
\text { No } \\
\text { No } \\
\text { No }\end{array}$ \\
\hline
\end{tabular}

QP/QS, pulmonary-to-systemic flow ratio; RVSP, right ventricular systolic pressure; LVSP, left ventricular systolic pressure; RVID, right ventricular septal defect. 
Table 3 Data of patients with ventricular septal defect and associated pathology

\begin{tabular}{|c|c|c|c|c|c|c|c|c|c|c|}
\hline $\begin{array}{l}\text { Case } \\
\text { no. }\end{array}$ & $\begin{array}{l}\text { Age }(y), \\
\text { sex }\end{array}$ & $\begin{array}{l}\text { Associated } \\
\text { pathology }\end{array}$ & $\begin{array}{l}\text { Aortic } \\
\text { saturation } \\
(\%)\end{array}$ & $\frac{P B F}{E P B F}$ & $\frac{S B F}{E P B F}$ & $\begin{array}{l}R V S P \\
(m m H g)\end{array}$ & $\begin{array}{l}\text { LVSP } \\
(\mathrm{mmHg})\end{array}$ & $\begin{array}{l}R V I D \\
(\mathrm{~mm}) \\
M \text { mode }\end{array}$ & $\begin{array}{l}\text { Paradoxical } \\
\text { septal motion } \\
M \text { mode }\end{array}$ & $\begin{array}{l}\text { Left-sided } \\
\text { echo } \\
\text { contrast }\end{array}$ \\
\hline $\begin{array}{l}1 \\
2\end{array}$ & $\begin{array}{l}29, \mathrm{~F} \\
21, \mathrm{~F}\end{array}$ & $\begin{array}{l}\text { Pulmonary } \\
\text { hypertension } \\
\text { Operated Fallot }\end{array}$ & 86 & 1.65 & 1.57 & 130 & 130 & - & - & Yes \\
\hline 3 & 19. $\mathrm{F}$ & $\begin{array}{l}\text { with residual } \\
\text { shunt }\end{array}$ & 96 & 3.75 & - & 51 & 100 & 28 & No & Yes \\
\hline 3 & $19, \mathrm{~F}$ & & 97 & 1.5 & - & 120 & 124 & 22 & No & Yes \\
\hline $\begin{array}{l}4 \\
5\end{array}$ & $31, F$ & & 90 & 1.43 & 1.36 & 110 & 124 & 30 & No & Yes \\
\hline 3 & $22, \mathrm{M}$ & $\begin{array}{l}1 \text { runcus } \\
\text { arteriosus }\end{array}$ & 88 & - & - & 110 & 110 & 37 & No & Yes \\
\hline 6 & $20, F$ & $\begin{array}{l}\text { Pulmonary } \\
\text { atresia }\end{array}$ & $78 \cdot 5$ & 1.5 & 1.62 & 145 & 145 & 10 & No & Yes \\
\hline 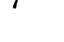 & $40, M$ & $\begin{array}{l}\text { Fallot, Potts } \\
\text { procedure }\end{array}$ & 90 & $1 \cdot 4$ & 1.6 & 130 & 140 & 18 & No & Yes \\
\hline
\end{tabular}

EPBF, effective pulmonary blood flow; PBF, pulmonary blood flow; SBF, systemic blood flow; RVSP, right ventricular systolic pressure; LVSP, left ventricular systolic pressure.

depth of the explored cross-section. Each frame consists of 40 basic lines and the dimensions of the rectangular cross-sectional image are $8 \times 16 \mathrm{~cm}$. The system operates at a rate of 50 frames per second. At the bottom of the picture, the electrocardiogram is displayed for timing purposes and its right-hand edge indicates the moment of the stopframe within the cardiac cycle. Images are recorded on video tape which allows their subsequent analysis in real time, slow motion, or stop-frame. Individual frames can be photographed using instant polaroid photography.

\section{EXAMINATION PROCEDURE}

The cross-sectional contrast studies were performed with the patients in the recumbent or slightly left lateral position.

Most attention was given towards visualisation on the left ventricular inflow and outflow portions, since, if any contrast material passed to the left-
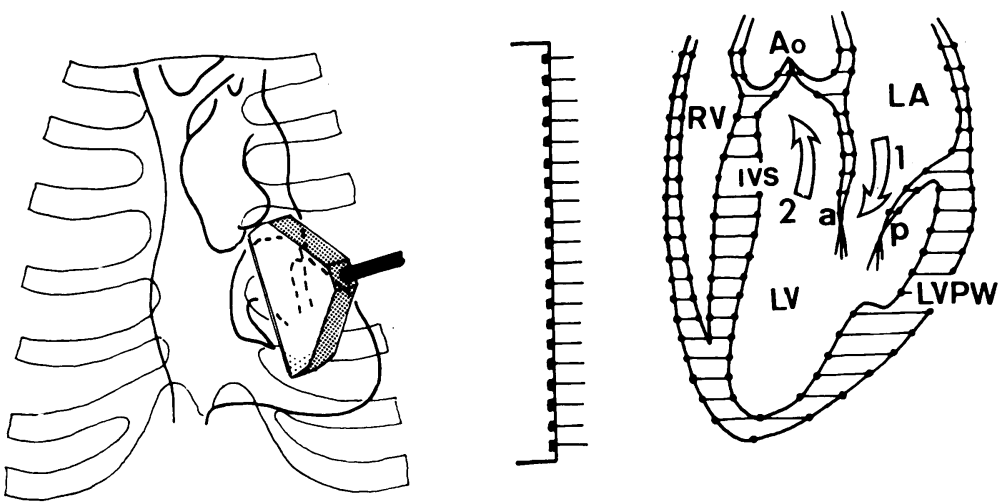

Fig. 1 The left panel shows the linear array transducer in the position on the chest wall which permits the visualisation of a sagittal cardiac cross-section passing through the long axis of the left ventricle. The right panel is a diagrammatic representation of the left ventricular long axis cross-section. The arrows indicate the left ventricular inflow (1) and outflow tracts (2). Echo contrast is most likely to be detected in these areas when it passes from the right to the left side of the heart.

Ao, aorta; $a$ and $p$, anterior and posterior mitral valve leaflets; IVS, interventricular septum; $L A$, left atrium; $L V P W$, left ventricular posterior wall; $R V$, right ventricle. 
sided cavities via an atrial septal defect, the chance of identifying it would be greatest in these areas. These structures are best studied in the crosssection following the long axis of the left ventricle which represents the entire $M$ mode echocardiographic view at any given moment within the cardiac cycle (Fig. 1). The interventricular septum is also seen in this cross-section which yields the greatest chance of detecting a right-to-left passage of echo contrast at ventricular level (Roelandt, 1977). A contrast study was considered positive when contrast echoes appeared in the left atrium, left ventricular inflow, and/or outflow tract. To avoid false positive tests as a result of overload effects, great care was taken to use the lowest possible gain settings of the instrument.

\section{ECHO CONTRAST PROCEDURE}

After initial standard $M$ mode and cross-sectional analysis, an 18-gauge Teflon venous sheath was inserted into a right antecubital vein. Through this venous route, injections of echo contrast material ( 5 to $10 \mathrm{ml}$ dextrose $5 \%$ in water) were carried out (on average 10 times) while cardiac cross-sections were continuously recorded on video tape. The success rate of obtaining an adequate echo contrast study was 100 per cent.

\section{Results}

In the control group of patients with no intracardiac shunt, acoustic opacification remained confined to the right ventricular cavity and outflow tract (Fig. 2). The right-sided contrast effect cleared rapidly, usually after 2 to 5 cardiac cycles, except in patients with tricuspid valve regurgitation, pulmonary regurgitation, or low cardiac output. The findings during ultrasonic contrast studies in the 20 patients with an atrial septal defect (group 1) are given in Table 1 . Of these, 15 patients had a classic atrial septal defect of the secundum type and no aortic desaturation was present by oximetry. However, a systolic right-to-left passage of echo contrast material was observed in 11 of these patients at atrial level (Fig. 3).

Five patients of group 1 had in addition to their left-to-right shunt, a right-to-left shunt which was demonstrated by oximetry (aortic oxygen saturation of less than $95 \%$ ). These 5 patients all showed leftsided appearance of echo contrast (Fig. 4). The

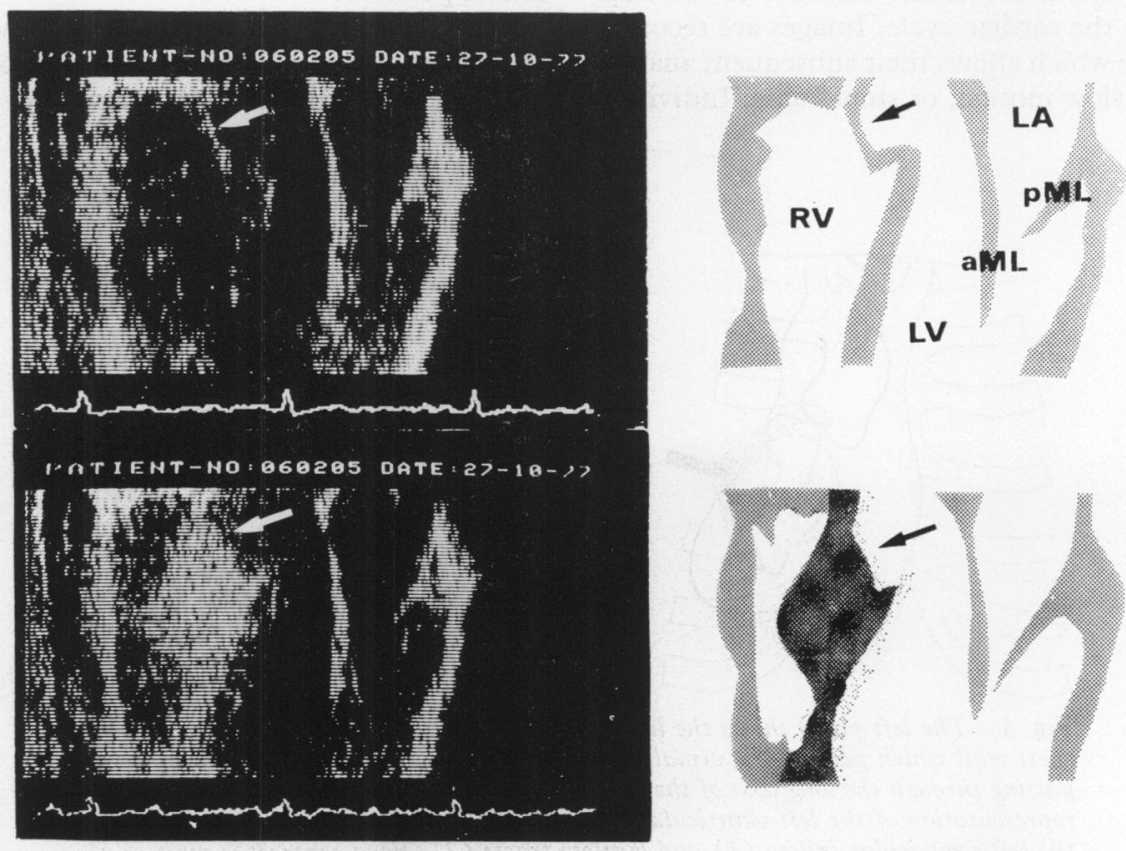

Fig. 2 Cross-sectional long axis images of the left ventricle before (upper frame) and after peripheral intravenous injection of dextrose 5 per cent in water (lower frame). The echo contrast which fills the right ventricular cavity is not detected in the left-sided cavities. The patient had an aneurysm of the membranous interventricular septum (arrow) which is delineated by the echo contrast material. 


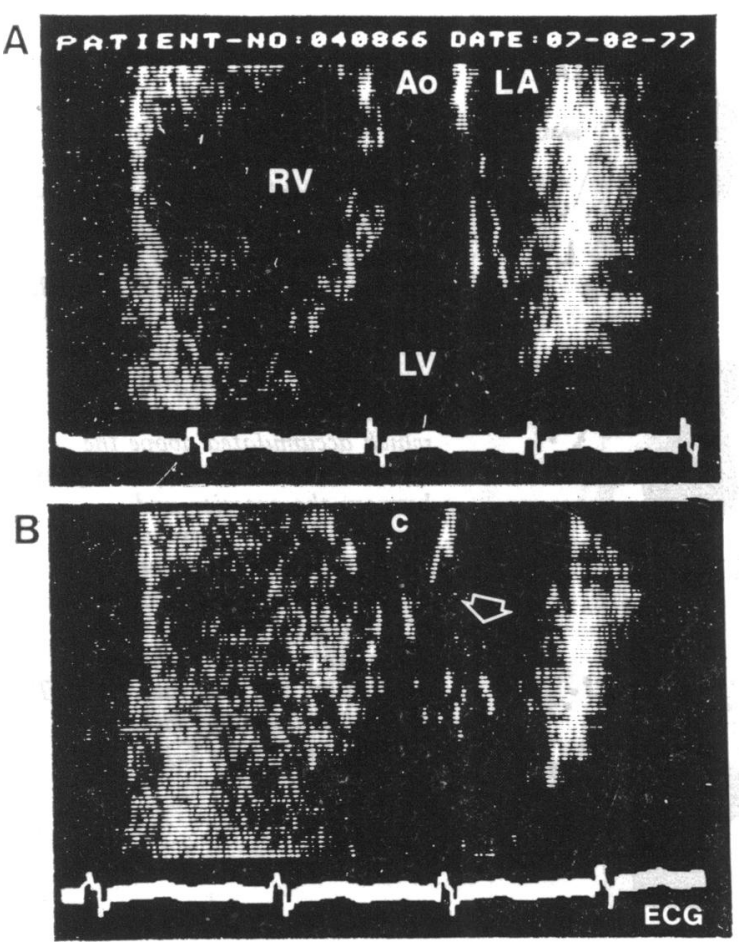

Fig. 3 Long axis cross-sections of a patient with an atrial septal defect of the secundum type before (frame $A$ ) and after peripheral vein injection (frame $B$ ). The echo contrast fills the right ventricular cavity $(R V)$ and appears in the left ventricular inflow tract during diastole (see arrow) indicating a right-to-left shunt at atrial level. Ao, aorta; $L A$, left atrium; $L V$, left ventricle; $C$, aortic valve cusps

echo contrast results of group 1 are summarised in Table 4.

In the group of patients with isolated ventricular septal defect and normal right-sided pressures; the echo contrast remained confined to the right ventricular cavity and outflow tract (Table 2).

The 7 patients with ventricular septal defect and associated pathology had in our series a ratio of right-to-left ventricular pressure exceeding 50 per cent. An early diastolic passage of echo contrast from within the right ventricular into the left ventricular outflow tract was demonstrated in all (Fig. 5, 6, and Table 3). In 2 of these patients, the aortic oxygen saturation was greater than 95 per cent.

\section{Discussion}

Early studies with ultrasonic contrast were carried
Table 4 Left-sided appearance of echo contrast and aortic saturation in 20 patients with atrial septal defect

\begin{tabular}{lll}
\hline \multirow{2}{*}{ Left-sided echo contrast } & Aortic & Saturation \\
\cline { 2 - 3 } & $\begin{array}{c}>95 \% \\
n=15\end{array}$ & $\begin{array}{c}<95 \% \\
n=5\end{array}$ \\
\hline Present & 11 & 5 \\
Absent & 4 & 0 \\
\hline
\end{tabular}

out during diagnostic catheterisation, with a catheter tip positioned in a cardiac cavity (Gramiak and Shah, 1968; Gramiak et al., 1969; Feigenbaum et al., 1970; Pieroni et al., 1973; Kerber et al., 1974; Seward et al., 1975). However, this additional information was of relatively low value since traditional techniques, routinely used during catheterisation, already provided the diagnosis.

The advantages of contrast echocardiography became readily accepted as soon as it was shown that the investigation could be performed outside the catheterisation laboratory with a peripheral vein injection (Valdes-Cruz et al., 1976; Seward et al., 1977).

During these studies the ultrasound beam is aimed along one of the standard $M$ mode axes (for example, through the right ventricular outflow tract, aorta, and left atrium) and kept stationary. The appearance of contrast in any of the cavities transected by the sound beam and its timing enables the examiner to study intracardiac blood flow patterns and to deduce the presence and location of a shunt. Using cross-sectional imaging techniques, the entire $M$ mode view rather than the structures along a single sound beam axis is visualised at once. Contrast-filled blood may so be seen to flow through a defect of the atrial or ventricular septum when the appropriate cross-sectional plane is selected for investigation. Direct evidence of the site of the defect may thus be provided. However, the visualisation of the interatrial septum is technically difficult with a linear array transducer of which the versatility in aiming the interrogating cross-section through the cardiac structures from the anterior chest wall is limited. Therefore, we decided to study the inflow and outflow tracts of the left ventricle to show a right-to-left shunt at atrial level. $M$ mode echocardiography was found to be of value for the detection of conditions associated with right-sided volume overload (Popp et al., 1969; Diamond et al., 1971; Kerber et al., 1972; McCann et al., 1972; Tajik et al., 1972a), but its specificity and sensitivity for the diagnosis of an atrial septal defect have been questioned (Tajik et al., 1972b; Hagan et al., 1974; Radtke et al., 

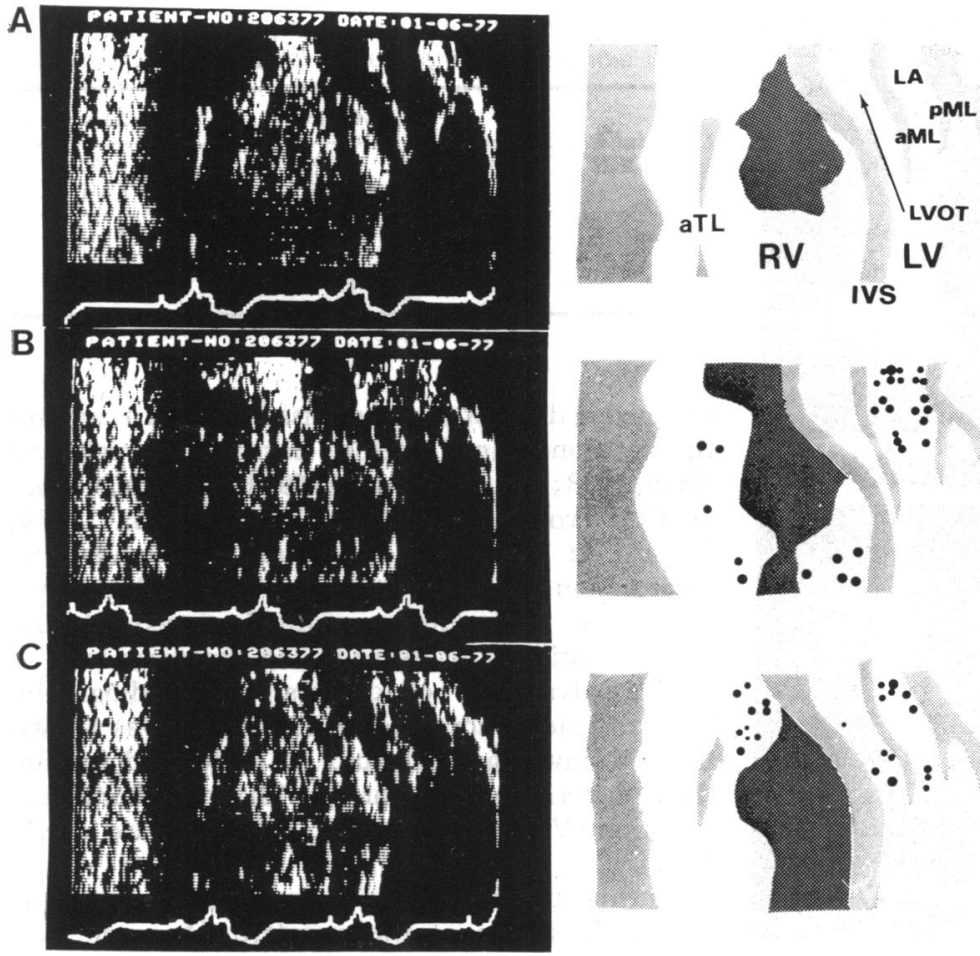

1976). Gated B-scan techniques (Matsumoto, 1973; Matsumoto et al., 1975) and real time crosssectional echocardiography (Dillon et al., 1977; Lieppe et al., 1977) should have several advantages over the $\mathrm{M}$ mode method for the direct visualisation of the interatrial septum. However, they may fail to show a localised gap in the mid-portion of the septum in patients with proven atrial septal defect. Furthermore, a false positive diagnosis can be made because 'drop-outs' occur (Roelandt et al., 1976). In other words, structural abnormalities cannot be ascertained unless additional evidence of an abnormal intracardiac flow pattern or the turbulence is obtained. Pulsed Doppler echocardiography (Johnson et al., 1973) and contrast echocardiography offer attractive methods for the demonstration of abnormal intracardiac blood flow patterns (Valdes-Cruz et al., 1976). Some workers have evaluated the diagnostic value of a negative contrast shadow during diastole in the right atrium after peripheral vein injection of Cardiogreen (Dillon et al., 1977). Here, the leftto-right flow of echo-free blood causes a filling defect at the level of the atrial septal defect in the opacified right atrium.

Detailed physiological studies with atrial pressure-
Fig. 4 Sagittal long axis crosssection obtained from a patient with Ebstein's anomaly and a right-to-left shunt at atrial level. On frame A, one sees ultrasonic contrast filling the dilated right ventricle $(R V)$. On frame $\mathrm{B}$, bright specks of echo contrast which accumulated above the mitral valve in early systole pass between the anterior and posterior mitral valve leaflets $(a M L)$ and $(p M L)$ into the inflow tract of the left ventricle $(L V)$ in early diastole.

They are detected in the left ventricular outflow tract (LVOT) at the onset of ventricular contraction (frame $\mathrm{C}$ ). flow dynamics, angiography, and dye dilution curves (Swan et al., 1954; Levin et al., 1968; Alexander et al., 1975), have consistently shown minor amounts of right-to-left shunting during early systole in patients with uncomplicated atrial septal defect. The detection of ultrasonic contrast in the left atrium and/or both the left ventricular inflow and outflow chambers can therefore be used as a positive test for the diagnosis of atrial septal defect. In our small group of 20 patients with atrial septal defect, a left-sided appearance of echo contrast could be shown in 16 patients. In the remaining 4 , no contrast could be detected, despite repeated studies. Nevertheless, contrast echocardiography appears to be a more sensitive method in demonstrating right-to-left shunting than oximetry since the latter method did not show aortic desaturation in any of these patients. This might be explained by the fact that each microbubble remains a detectable entity wherever it is located in the left atrium, left ventricular inflow, or outflow tracts of which a large volume is explored by crosssectional echocardiography. On the contrary, detection of oxygen depleted blood is dependent on the volume of right-to-left shunting and also on the position of the catheter tip used for blood 

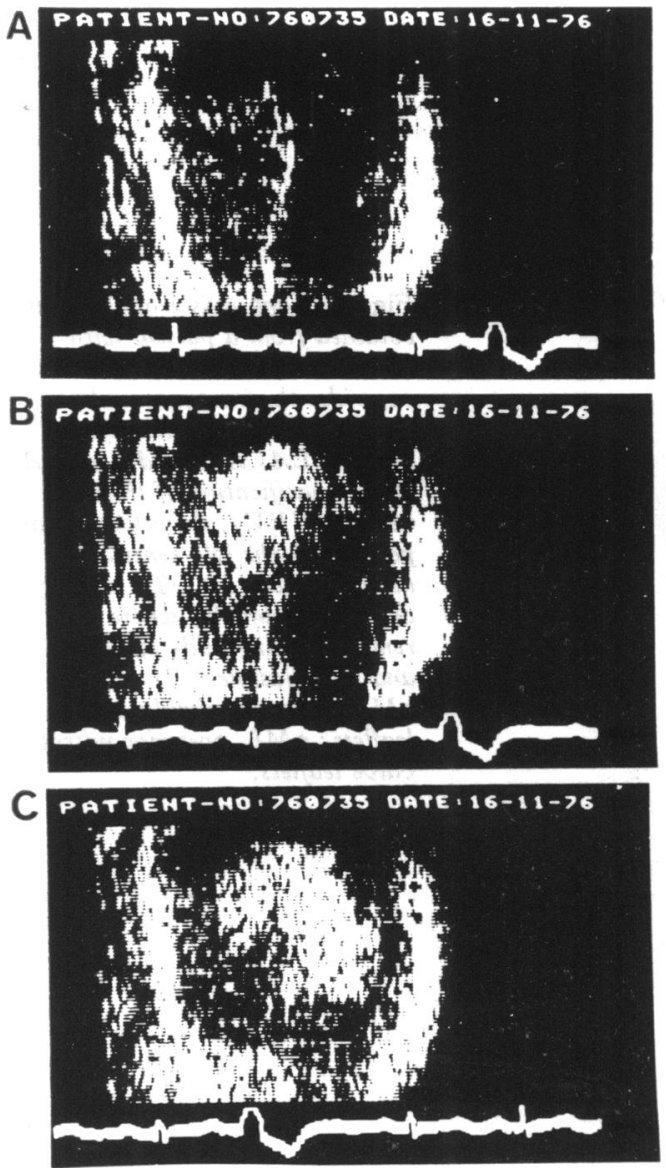

Fig. 5 Cross-sections through both the right $(R V)$ and left ventricle $(L V)$ obtained from a patient with ventricular septal defect. Persistent ductus arteriosus and Eisenmenger syndrome before (frame A) and after opacification of the right ventricular cavity by echo contrast after peripheral venous injection (frame $\mathrm{B}$ ). The echo contrast passes into the left ventricular outflow tract and left ventricle via the ventricular septal defect in early diastole (frame $\mathrm{C}$ ). $A o$, aorta; $L A$, left atrium.

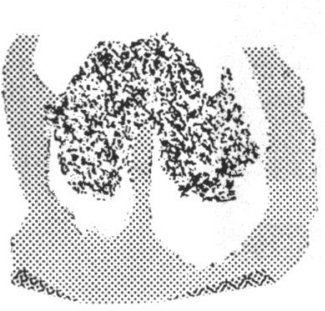

sampling. Thus, detection of a few contrast microbubbles by two-dimensional echo is achieved with a higher level of probability.

In patients with a ventricular septal defect, a right-to-left passage of echo contrast occurred in the presence of right ventricular peak systolic pressure above 50 per cent of the left ventricular peak systolic pressure and it appeared in the left ventricular outflow tract early during ventricular diastole (Levin et al., 1967).

Timing analysis disclosed that the shunt flow occurred during the isovolumic relaxation phase, that is after aortic valve closure and before mitral opening (Assad-Morell et al., 1976; Serruys et al., 1977). Two patients failed to demonstrate a detectable oximetric right-to-left shunt, though a few microbubbles in the aorta could be shown. Our study indicates the common occurrence of 'bidirectionality' in uncomplicated atrial septal defect.
The demonstration of echo contrast in the left-sided heart chambers can be used as a diagnostic test of an atrial septal defect in patients presenting with non-specific physical examination and $M$ mode findings of right ventricular volume overload. It is helpful to ascertain an atrial septal defect in patients with Ebstein's anomaly. The 'bidirectionality' of the shunt, however, has more serious implications in patients with ventricular septal defects where it indicates a raised right ventricular pressure caused either by pulmonary stenosis or by increased pulmonary vascular resistance.

In conclusion, real time cross-sectional echo contrast studies with peripheral venous injections of 5 per cent dextrose in water have shown that physiological information is obtained together with the actual anatomy of the heart. The demonstration of direction and timing of intracardiac right-to-left shunts, even when small, appears to be greatly 


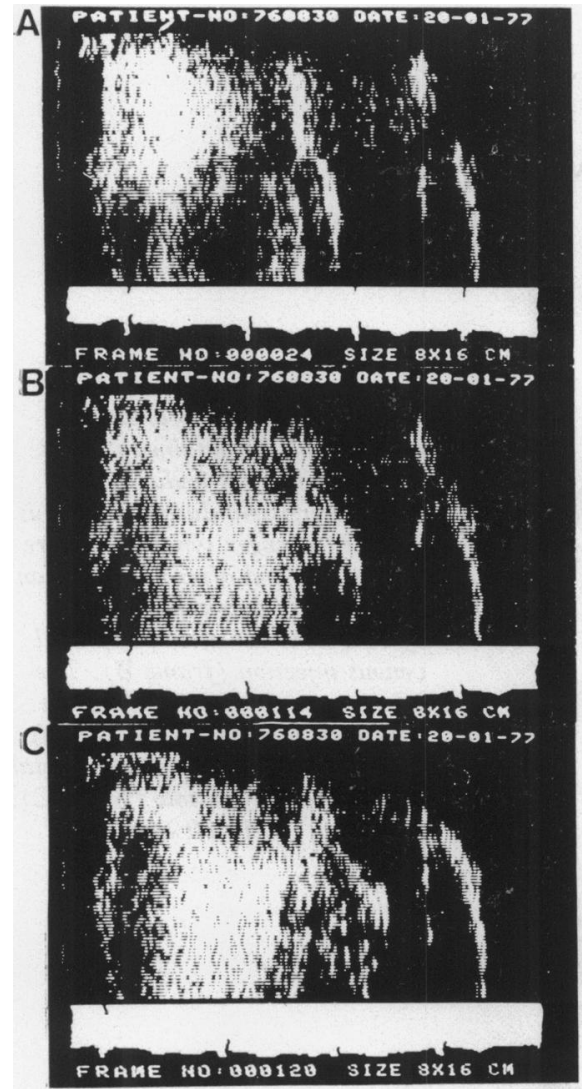

facilitated. The technique may become the most cost-effective direct method by which to diagnose and localise the site of these intracardiac septal defects non-invasively.

\section{References}

Alexander, J. A., Rembert, J. C., Sealy, W. C., and Greenfield, J. C. (1975). Shunt dynamics in experimental atrial defects. Fournal of Applied Physiology, 39, 281-286.

Assad-Morell, J. L., Seward, J. B., Tajik, A. J., Hagler, D. J., Giuliani, E. R., and Ritter, D. G. (1976). Echophonocardiographic and contrast studies in conditions associated with systemic arterial trunk overriding the ventricular septum. Circulation, 53, 663-673.

Bing, R. J., Vandam, L. D., and Gray, G. D. (1947). Physiological studies in congenital heart disease. Bulletin of the fohns Hopkins Hospital, 80, 107-120.

Diamond, M. A., Dillon, J. C., Haine, C. L., Chang, S., and Feigenbaum, H. (1971). Echocardiographic features of atrial septal defect. Circulation, 43, 129-135.

Dillon, J. C., Weyman, A. E., Feigenbaum, H., Eggleton, R. C., and Johnston, K. (1977). Cross-sectional echocardiographic examination of the interatrial septum. Circulation, 55, 115-120.

Feigenbaum, H., Stone, J. M., Lee, D. A., Nasser, W. K., and Chang, S. (1970). Identification of ultrasound echoes from the left ventricle by use of intracardiac injection of indocyanine green. Circulation, 41, 615-621.

Flamm, M. D., Cohn, K. E., and Hancock, E. W. (1969). Measurements of systemic cardiac output at rest and exercise in patients with atrial septal defect. American fournal of Cardiology, 23, 258-265.

Gramiak, R., and Shah, P. M. (1968). Echocardiography of the aortic root. Investigative Radiology, 3, 356-366.

Gramiak, R., Shah, P. M., and Kramer, D. H. (1969). Ultrasound cardiography: contrast study in anatomy and function. Radiology, 92, 939-948.

Hagan, A. D., Francis, G. S., Sahn, D. J., Karliner, J. S., Friedman, W. F., and O'Rourke, R. A. (1974). Ultrasound evaluation of systolic anterior septal motion in patients with and without right ventricular volume overload. Circulation, 50, 248-254.

Johnson, S. L., Baker, D. W., and Dodge, H. T. (1973) Doppler echocardiography: the location of cardiac murmurs. Circulation, 48, 810-822.

Kerber, R. E., Dippel, W. F., and Abboud, F. M. (1972). Abnormal motion of the interventricular septum in right ventricular volume overload: experimental and clinical echocardiographic studies. Circulation, 48, 86-96.

Kerber, R. E., Kioschos, J. M., and Lauer, R. M. (1974). Use of an ultrasonic contrast method in the diagnosis of valvular regurgitation and intracardiac shunts. American fournal of Cardiology, 34, 722-727. 
Levin, A. R., Spach, M. S., Boineau, J. P., Canent, R. V., jun, Capp, M. P., and Jewett, P. H. (1968). Atrial pressureflow dynamics in atrial septal defects (secundum type). Circulation, 37, 476-488.

Levin, A. R., Spach, M. S., Canent, R. V., jun, Boineau, J. P., Capp, M. P., Jain, V., and Barr, R. C. (1967). Intracardiac pressure-flow dynamics in isolated ventricular septal defects. Circulation, 35, 430-441.

Lieppe, W., Scallion, R., Behar, V. S., and Kisslo, J. A. (1977). Two-dimensional echocardiographic findings in atrial septal defect. Circulation, 56, 447-456.

Ligtvoet, C. M., Ridder, J., Lancee, C. T., Hagemeijer, F., and Vletter, W. B. (1977). A dynamically focussed multiscan system. In Echocardiology, pp. 313-324, ed. N. Bom. Nijhoff, The Hague.

McCann, W. D., Harbold, N. B., and Giuliani, E. R. (1972). The echocardiogram in right ventricular overload. fournal of the American Medical Association, 221, 1243-1245.

Matsumoto, M. (1973). Ultrasonic features of interatrial septum: its motion analysis and detection of its defects. fapanese Circulation fournal, 37, 1383-1384.

Matsumoto, M., Nimura, Y., Matsuo, H., Nagata, S., Mochizuki, S., Sakakibara, H., and Abe, H. (1975). Interatrial septum in B mode and conventional echocardiograms -a clue for the diagnosis of congenital heart disease. Fournal of Clinical Ultrasound, 3, 29-37.

Pieroni, D., Varghese, P. J., and Rowe, R. D. (1973). Echocardiography to detect shunt and valvular incompetence in infants and children (abstract). Circulation, 47 and 48, Suppl. IV, 81.

Popp, R. L., Wolfe, S. B., Hirata, T., and Feigenbaum, H. (1969). Estimation of right and left ventricular size by ultrasound. A study of the echoes from the interventricular septum. American Fournal of Cardiology, 24, 523-530.

Radtke, W. E., Tajik, A. J., Gau, G. T., Schattenberg, T. T., Giuliani, E. R., and Tancredi, R. G. (1976). Atrial septal defect: echocardiographic observations. Studies in 120 patients. Annals of Internal Medicine, 84, 246-253.

Roelandt, J. (1977). Practical Echocardiology. Research Studies Press, Forest Grove.

Roelandt, J., Van Dorp, W. G., Bom, N., Laird, J. D., and Hugenholtz, P. G. (1976). Resolution problems in echocardiology: a source of interpretation errors. American fournal of Cardiology, 37, 256-262.

Serruys, P. W., Vletter, W. B., Hagemeijer, F., and Ligtvoet, C. M. (1977). Bidimensional real time echocardiological visualisation of a ventricular right-to-left shunt following peripheral vein injection. European fournal of Cardiology, 6, 99-107.

Seward, J. B., Tajik, A. J., Hagler, D. J., and Ritter, D. G. (1977). Peripheral venous contrast echocardiography. American fournal of Cardiology, 39, 202-212.

Seward, J. B., Tajik, A. J., Spangler, J. G., and Ritter, D. G. (1975). Echocardiographic contrast studies. Initial experence. Mayo Clinic Proceedings, 50, 163-192.

Swan, H. J. C., Burchell, H. B., and Wood, E. H. (1954). The presence of venoarterial shunts in patients with interatrial communications. Circulation, 10, 705-713.

Tajik, A. J., Gau, G. T., Ritter, D. G., and Schattenberg, T. T. (1972a). Echocardiographic pattern of right ventricular diastolic volume overload in children. Circulation, 46, 36-43.

Tajik, A. J., Gau, G. T., Schattenberg, T. T., and Ritter, D. G. (1972b). Normal ventricular septal motion in atrial septal defect. Mayo Clinic Proceedings, 47, 635-638.

Valdes-Cruz, L. M., Pieroni, D. R., Roland, J. M. A., and Varghese, P. J. (1976). Echocardiographic detection of intracardiac right-to-left shunts following peripheral vein injection. Circulation, 54, 558-562.

Requests for reprints to Dr Jos Roelandt, Thoraxcenter, PO Box 1738, Rotterdam, the Netherlands. 